\title{
Hubungan Perineum Massage, Paritas, Dan Berat Badan Bayi Baru Lahir Dengan Kejadian Rupture Perineum
}

\author{
Dewi Suri Damayanti, Okta Zenita Siti Fatimah, Dewi Fajarwati \\ Prodi Kebidanan Fakultas Kesehatan Universitas MH. Thamrin \\ Email : dewi.suri.damayanti@gmail.com
}

\begin{abstract}
Abstrak
Pada proses persalinan normal terdapat rlsiko perdarahan penyebab terjadinya perdarahan salah satunya dikarenakan adanya ruptur perineum. Ruptur perineum yang tidak tertangani dengan baik akan meningkatkan resiko infeksi, sehingga dapat meningkatkan angka mobiditas dan mortalitas ibu. Tujuan dilakukan penelitian ini adalah untuk mengetahui angka kejadian rupture perineum serta faktor yang berhubungan terjadinya rupture perineum pada ibu bersalin. Metode penelitian kuantitatif secara cross sectional, jumlah responden penelitian ini adalah 169 responden. Pengumpulan data menggunakan data primer dengan mengisi kuesioner melalui google form. Teknik analisis mengunakan univariat dan bivariate (Uji Chi Square). Hasil penelitian ini didapatkan reponden yang mengalami rupture perineum pada saat bersalin sebesar $94,7 \%$, tidak melakukan massage uterus sebesar $68 \%$, paritas primipara sebesar $42 \%$, dan berat badan lahir bayi normal sebesar $94.1 \%$. Pada analisa bivariat diperoleh faktor yang berhubungan dengan kejadian rupture perineum yaitu massage uterus ( $p$ value 0.031 dengan nilai $O R=4.667$, artinya ibu yang tidak melakukan massage perineum mempunyai pelung 4.67 kali untuk mengalami rupture perineum. Dengan menerapkan asuhan massage perineum pada saat kehamilan dapat menggurangi risiko terjadinya rupture perineum pada ibu bersalin
\end{abstract}

Kata kunci : Rupture perineum, massage perineum, paritas, dan berat badan bayi baru lahir

\begin{abstract}
In the process of vaginal birth, there is a risk of bleeding, one of the causes of bleeding is due to perineal rupture. Perineal rupture that is not handled properly will increase the risk of infection, so that it can increase the rate of maternal morbidity and mortality. The purpose of this study was to determine the incidence of perineal rupture and the factors associated with the occurrence of perineal rupture in mothers who gave birth. The quantitative research method is cross sectional, the number of respondents in this study were 169 respondents. Data collection uses primary data by filling out a questionnaire via google form. The analysis technique used univariate and bivariate (Chi Square Test). The results of this study found that respondents who experienced perineal rupture during delivery were $94.7 \%$, did not perform uterine massage by $68 \%$, primiparous parity was $42 \%$, and normal birth weight of infants was $94.1 \%$. In the bivariate analysis, the factors associated with the incidence of perineal rupture were obtained, namely uterine massage $(p$ value 0.031 with an OR value $=$ 4.667, meaning that mothers who did not perform perineal massage had 4.67 times the opportunity to experience perineal rupture. By applying perineal massage care during pregnancy can reduce the risk of perineal rupture in the mother
\end{abstract}

Key words : perineal rupture, perineal massage, parity, and body weight of newborns

http://ejournal.urindo.ac.id/index.php/jukmas

Article History :

Submitted 30 Desember 2020, Accepted 28 April 2021, Published 30 April 2021 


\section{PENDAHULUAN}

Robekan jalan lahir penyebab kedua perdarahan setelah atonia uteri, terjadi pada hampir persalinan pertama dan tidak jarang juga pada persalinan berikutnya. Orang yang baru pertama kali melahirkan atau seorang primipara ketika terjadi peristiwa "kepala keluar pintu" biasanya perineumnya mengalami ketegangan sehingga terjadi robekan pada pinggir depannya. Luka-luka biasanya ringan tetapi kadang-kadang terjadi juga luka yang luas dan berbahaya. ${ }^{[1]}$

Laserasi pada ruptur perineum dapat mengakibatkan perdarahan, pada laserasi derajat I dan II jarang terjadi perdarahan, namun pada laserasi ke III dan IV sering menyebabkan perdarahan pospartum. [2] Ruptur perineum dapat menyebabkan disfungsi organ reproduksi wanita, sumber perdarahan, sumber atau jalan keluar masuknya infeksi, serta dapat menyebabkan kematian karena perdarahan atau sepsis, oleh karena itu rupture perineum perlu mendapatkan perhatian ${ }^{[3]}$

Faktor penyebab robekan perineum diantaranya adalah faktor ibu (paritas,meneran) faktor janin (berat badan bayi baru lahir, presentasi muka, presentasi dahi, presentasi bokong), faktor persalinan pervaginam dengan tindakan (vacuum ekstraksi, ekstraksi cunam/forcep, embriotomy, persalinan partus presipitatus, dan faktor penolong persalinan. Penelitian Puslitbang Bandung di provinsi Indonesia tahun 2009-2010 menyatakan bahwa satu dari lima ibu bersalin yang mengalami ruptur perineum akan meninggal dunia. ${ }^{[5]}$ Masih cukup tinggi angka kejadian robekan perineum di puskesmas Kecamatan pasar minggu yang di pengaruhi oleh berbagai faktor terlihat berdasarkan data tahun 2014 (juli s/d Desember) dari 152 kasus persalinan pervaginam, sebanyak 86 kasus $(56,5 \%)$ mengalami robekan persalinan ${ }^{[6]}$

Penelitian ini mempunyai tujuan untuk mengetahui berapa angka kejadian ruptur perineum serta faktor yang berhubungan dengan terjadinya ruptur perineum pada ibu bersalin di Bidan Praktik Jakarta Timur Tahun 2020. Manfaat dari hasil penelitian ini merupakan masukan bagi pembangunan program pelayanan kesehatan di bidang kebidanan, dalam upaya penurunan angka morbiditas dan mortalitas ibu khususnya pada kasus perdarahan yang disebabkan oleh rupture perineum.

\section{METODE PENELITIAN}

Penelitian ini bersifat kuantitatif dengan desain cross sectional

Populasi dalam penelitian merupakan ibu yang bersalin pada bulan Januari 2020 sampai dengan September 2020 di bidan 
praktik Jakarta Timur yang terdapat asuhan antenatal massage perineum berjumlah 389 orang. Berdasarkan rumus Slovin dengan taraf signifikansi 0.05 jumlah sampel penelitian ini yaitu 198 responden .

Teknik pengambilan sampel pada penelitian ini adalah nonprobability sampling secara accidental sampling

Kriteria inklusi pada penelitian ini adalah adanya kecocokan data identitas reponden berdasarkan pengisian google form dengan data yang ada di bidan praktik. Kriteria ekslusi yaitu ibu bersalin berdasarkan data bidan praktik yang tidak mengisi google form setelah dilakukan reminder sebanyak $3 x$

Cara pengambilan data secara primer menggunakan instrument penelitian berupa kuesioner yang dimasukkan kedalam aplikas google form, berupa butir - butir pertanyaan yang disusun oleh peneliti terkait identitas responden, massage uterus, paritas ibu, dan berat badan bayi ibu ketika baru lahir.

Analisa data pada penelitian ini yaitu analisis univariat dan bivariate. Data yang dianalisis secara univariat yaitu; rupture perineum, perineum massage, paritas, dan berat badan bayi baru lahir. Kemudian dilanjutkan dengan analisis bivariate (Uji Chi Square), pada variable perineum massage dengan kejadian rupture perineum dan variable paritas dengan kejadian rupture perineum tabel yang digunakan $2 \times 2$, dan ada nilai $\mathrm{E}<5$ maka uji yang digunakan adalah fisher's exact test.

\section{HASIL PENELITIAN DAN PEMBAHASAN}

Pada hasil peneitian ini terdapat keterbatasan yaitu jumlah responden yang kurang dari target 198 responden. Peneliti telah melakukan reminder sebanyak $3 x$ melalui nomor telpon yang tertera di buku register untuk pengisian kuesiner melalui google form didapatkan 181 data yang masuk di google form selanjutnya dilakukan cleaning data terdapat 1 data yang tidak dapat di cocokan dengan data di register klinik dan 11 data duplikat sehingga data responden yang kami peroleh untuk dianalisis lebih lanjut sebesar 169 responden 
Table 1

Distribusi Responden Berdasarkan Ruptur Perineum, Perineum Massage, Paritas, berat badan bayi baru lahir

\begin{tabular}{ccc}
\hline Ruptur perineum & Jumlah & Persentase \\
\hline Tidak rupture & 9 & 5.3 \\
Rupture & 160 & 94.7 \\
Perineum Massage & & \\
lya & 54 & 32.0 \\
Tidak & 115 & 68.0 \\
Paritas & & \\
Multipara & 98 & 58.0 \\
Primipara & 71 & 42.0 \\
Berat Badan Bayi Baru Lahir & & \\
BBLR & 10 & 5.9 \\
Normal & 159 & 94.1 \\
\hline
\end{tabular}

Berdasarkan Tabel 1. Menyatakan bahwa distribusi responden berdasarkan terjadinya rupture perineum yang terbanyak adalah reponden yang mengalami rupture perineum yaitu 160 orang (94.7\%), distribusi responden berdasarkan perineum massage yang terbanyak adalah reponden yang tidak melakukan perineum massage yaitu 115 orang (68.0\%), distribusi responden berdasarkan paritas lebih banyak pada reponden yang multipara yaitu 98 orang (58.0\%), distribusi responden berdasarkan berat badan bayi baru lahir yang terbanyak adalah reponden yang berat badan lahir bayi normal yaitu 159 orang $(94,1 \%)$.
Analisis univariat dari hasil penelitian ini menunjukkan bahwa responden yang mengalami rupture perineum yaitu $94,7 \%$. Pada hasil penelitian Suryani bulan Juli sampai dengan Agustus 2011 kejadian ruptur perineum pada persalinan normal didapatkan hasil sebanyak $71 \%$ yang mengalami rupture perineum di Rumah Bersalin Atiah Kota $J_{a m b i}{ }^{[5]}$

Tingginya cakupan ini bisa disebabkan oleh beberapa faktor, baik dari janin maupun materna 
Tabel 2

Hubungan Perineum Massage, Paritas, dan Berat Badan Bayi Baru Lahir Dengan Kejadian Rupture Perineum di Bidan Praktik Jakarta Timur

\begin{tabular}{|c|c|c|c|c|c|c|c|c|}
\hline \multirow[t]{3}{*}{ Variabel } & \multicolumn{4}{|c|}{ Rupture Perineum } & \multirow{2}{*}{\multicolumn{2}{|c|}{ Total }} & \multirow{3}{*}{$\begin{array}{c}\text { OR } \\
(95 \% \mathrm{Cl})\end{array}$} & \multirow{3}{*}{$\begin{array}{c}\mathrm{P} \\
\text { Value }\end{array}$} \\
\hline & \multicolumn{2}{|c|}{ Tidak Rupture } & \multicolumn{2}{|c|}{ Rupture } & & & & \\
\hline & $\mathrm{n}$ & $\%$ & $\mathrm{n}$ & $\%$ & $\mathrm{n}$ & $\%$ & & \\
\hline \multicolumn{9}{|c|}{ Perineum Massage } \\
\hline Iya & 6 & 11.1 & 48 & 88.9 & 54 & 100 & 4.667 & \\
\hline Tidak & 3 & 2.6 & 112 & 97.4 & 115 & 100 & $1.121-19.434$ & 0.031 \\
\hline \multicolumn{9}{|l|}{ Paritas } \\
\hline Multipara & 8 & 8.2 & 90 & 91.8 & 98 & 100 & 6.222 & \\
\hline Primipara & 1 & 1.4 & 70 & 98.6 & 71 & 100 & $0.760-50.923$ & 0.081 \\
\hline \multicolumn{9}{|c|}{ BB Bayi Baru Lahir } \\
\hline BBLR & 0 & 0 & 10 & 100 & 10 & 100 & - & \\
\hline Normal & 9 & 5.7 & 150 & 94.3 & 159 & 100 & & 1.000 \\
\hline Total & 9 & 5.3 & 160 & 94.7 & 169 & 100 & & \\
\hline
\end{tabular}

Berdasarkan Tabel 2 didapatkan hasil hubungan antara perineum massage dengan kejadian rupture perineum, diperoleh sebanyak 48 (88.9\%) ibu yang melakukan massage perineum mengalami rupture perineum. Sedangkan diantara ibu yang tidak melakukan massage perineum, ada 112 (97.4\%) yang mengalami ruptur perineum. Berdasarkan hasil uji statistik dengan nilai $p=0.031$ maka dapat disimpulkan ada perbedaan proporsi kejadian rupture perineum antara ibu yang melakukan massage perineum dengan ibu yang tidak melakukan massage perineum (ada hubungan signifikan antara perineum massage dengan rupture perineum). Dari hasil analisis di peroleh nilai $\mathrm{OR}=4.667$, artinya ibu yang tidak melakukan massage perineum mempunyai pelung 4.67 kali untuk mengalami rupture perineum

Hasil penelitian ini sejalan dengan penelitian Anggraini (2015) di dapatkan hasil ada hubungan yang bermakna antara pijat perineum dengan robekan jalan lahir, dengan nilai $\mathrm{OR}=10,280$ ( $\mathrm{Cl}: 4,568-23,135)$, yang berarti ibu yang tidak melakukan pijat perineum berpeluang mengalami 10,280 kali lebih besar mengalami robekan jalan lahir dibandingkan dengan ibu yang melakukan pijat perineum ${ }^{[13]}$ 
Penelitian yang diterbitkan di Amerika Journal Obstetrican and Gynecology menyimpulkan bahwa pijat perineum selama kehamilan dapat melindungsi fungsi perineum paling tidak dalam 3 bulan pasca melahirkan. The Cochrane Review merekomendasikan bahwa pijat perineum harus selalu dijelaskan pada ibu hamil agar mereka mengetahui keuntungan dari pijat perineum ini $^{[17]}$

Menurut syafrudin (2012) dalam Rochmayanti (2019) pijat perineum adalah mempersiapkan jaringan perineum untuk proses peregangan selama proses persalinan sehingga mengurangi robekan perineum dan mempercepat proses penyembuhannya ${ }^{[17] .}$ Tujuan dilakukannya pemijatan ini adalah untuk membantu elastisitas perineum ibu ${ }^{[18]}$

Berdasarkan Tabel 2 Hasil analisis antara paritas dengan kejadian rupture perineum diperoleh sebanyak 90 (91.8\%) ibu multipara yang mengalami rupture perineum dan pada ibu yang primipara, ada 70 (98.6\%) yang mengalami ruptur perineum. Berdasarkan hasil uji statistik didapatkan nilai $p=0.081$ maka dapat disimpukan tidak ada perbedaan proporsi kejadian rupture perineum antara ibu multipara dengan ibu primipara (tidak ada hubungan yang signifikan antara paritas dengan rupture perineum).
Berdasarkan hasil penelitian di Rumah Bersalin Atiah kota Jambi didapatkan analisis hubungan paritas dengan rupture perineum pada persalinan normal, pada persalinan primipara ada 16 responden $(94,1 \%)$ rupture perineum, dari hasil uji statistic menujukkan adanya hubungan yang bermakna antara paritas dengan kejadian rupture perineum pada persalinan normal ${ }^{[5]}$. Penelitian yang dilakukan oleh Suryani sejalan dengan penelitian di RSU Imelda Pekerja Indonesia Medan yang menyatakan ada hubungan yang bermakna antara paritas dengan rupture perineum ${ }^{[7]}$.Pada Penelitain yang dilakukan Robekan Perineum pada Persalinan Vaginal di Bidan Praktek Swasta (BPS) Daerah Istimewa Yogyakarta terdapat hubungan antara paritas dengan robekan perineum, bila paritas makin kecil kejadian robekan perineum meningkat ${ }^{[20] .}$.

Penelitian ini sejalan dengan penelitian di Puskesmas Puri Kabupaten Mojokerto tahun 2017 ${ }^{[21]}$ dan hasil penelitian yang dilakukan di RSUD Mutilan yang menyatakan tidak terdapat hubungan yang bermakna antara paritas dengan rupture perineum. Hal ini disebabkan karena setiap ibu mempunyai tingkat keelastisan perineum yang berbedabeda $^{[21]}$.

Menurut Oxorn (2010) banyak wanita mengalami robekan perineum pada 
persalinan yang pertama ${ }^{[9]}$. Dengan perineum yang masih utuh pada primi akan mudah terjadi robekan perineum ${ }^{[4]}$.

Hasil penelitian ini tidak sejalan dengan hasil penelitian Suryani (2013) dan Sigalingging (2018) serta teori yang ada, dikarenakan faktor ibu yang menyebabkan terjadinya rupture perineum tidak hanya di sebabkan oleh faktor paritas tetapi dapat disebabkan oleh faktor yang lainnya yaitu meneran ${ }^{[4]}$.

Berdasarkan tabel 2 didapatakan hasil dari 160 responden (94,7\%) yang mengalami rupture terdiri dari 10 responden BBLR dan 150 responden dengan berat badan lahir bayi normal. Untuk kategori reponden yang tidak rupture perineum sebanyak 9 responden (5.3\%) yang keseluruhnnya terdiri dari reponden dengan berat badan bayi normal.

Masih banyaknya kejadian rupture perineum disebabkan karena penyebab terjadinya robekan perineum tidak hanya terdiri oleh berat badan bayi baru lahir akan tetapi banyak faktor lainnya baik dari faktor janin maupun faktor maternal.

\section{KESIMPULAN DAN SARAN}

Gambaran kejadian rupture menunjukkan bawa responden yang menglami rupture perineum ketika bersalin mencapai angka 94,7\%. Tingginya cakupan ini bisa disebabkan oleh beberapa faktor, baik dari janin maupun maternal.

Dua dari tiga variable yang diteliti menunjukkan tidak ada hubungan yang signifikan yaitu paritas dan berat badan bayi baru lahir. Pada variable perineum massage berdasarkan hasil uji statistic menunjukkan hasil ada hubungan yang signifikan antara perineum massage dengan rupture perineum dan hasil analisis di peroleh nilai $\mathrm{OR}=4.667$, artinya ibu yang tidak melakukan massage perineum mempunyai peluang 4.67 kali untuk mengalami rupture perineum.

Bagi tenaga kesehatan terutama bidan, disarankan agar mengikuti kegiatan yang dapat meningkatkan pengetahuan dan keterampilan seperti midwifery update, khususnya mengenai cara pencegahan rupture perineum ketika bersalin. Serta dapat megaplikasikan teknik massage perineum, memberikan penyuluhan dan pelatihan ke klien dan keluarga. Sehingga Penerapan asuhan antenatal massage perineum dapat dilakukan oleh tenaga kesehatan maupun ibu dan keluarga .

Penelitian dengan karakteristik responden yang sama namun menggunakan rancangan pre-ekperimen kelompok intervensi dan kelompok kontrol agar dapat mengali lebih dalam mengenai kejadian rupture perineum ketika bersalin. Sehingga dapat menurunkan angka kejadian rupture 
perineum

\section{UCAPAN TERIMAKASIH}

Kegiatan penelitian ini dapat terlaksana berkat dukungan dan bimbingan berbagai pihak. Untuk itu kami mengucapkan terimakasih kepada Universitas $\mathrm{MH}$. Thamrin, Klinik Anny Rahardjo serta semua pihak yang telah membantu sehingga laporan penelitian ini dapat diselesaikan.

\section{DAFTAR PUSTAKA}

[1]. Prawirohardjo S. Ilmu Kebidanan. Jakarta: PT. Bina Pustaka; 2014. 982 p.

[2]. Varney H. Buku Ajar Asuhan Kebidanan. 2nd ed. Jakarta: EGC; 2008.

[3]. Mochtar R. Sinopsis Obstetri. Jakarta: EGC; 2011.

[4]. Nurjasmi E. Buku Acuan Midwifery Update 2016. Jakarta: Pengurus Pusat Ikatan Bidan Indonesia; 2016. 79-82 p.

[5]. Suryani. Perineum Pada Persalinan Normal. 278 J Kesehat [Internet]. 2013;IV(Faktor-Faktor Yang Berhubungan Dengan Ruptur Perineum Pada Persalinan Normal):277-83. Available from: https://ejurnal.poltekkestjk.ac.id/index.php/JK/article/view/12
[6] . Marhamah M. 'Faktor-Faktor Yang Berhubungan dengan Kejadian Rupture Perineum pada Persalinan Pervagina di Puskesmas Kecamatan Pasar Minggu Jakarta Selatan. Semin Nas Mullti Displin IImu [Internet]. 2017; V(November):473-81. Available from:

http://conference.raharia.ac.id/index.p hp/snmdi1/snmdi1/paper/view/99/10 $\underline{8}$

[7] . Sigalingging $M$, Sikumbang SR. Faktor yang Berhubungan dengan Terjadinya Rupture Perineum Pada Ibu Bersalin di RSU Imelda Pekerja Indonesia Medan. J Bidan Komunitas. 2018;1(3):161.

[8]. Wiknjosastro H. Ilmu Kandungan. 2nd ed. Jakarta: EGC; 2008.

[9]. Oxorn, Harry and Forle WR. IImu kebidanan: Patologi dan Fisiologi Persalinan. 1st ed. Hakimi M, editor. Yogyakarta: C.V Andi offset; 2010. 451 p.

[10]. Aprillia Y. Hipnostetri : Rileks, Nyaman, dan Aman Saat Hamil \& Melahirkan. Jakarta: GagasMedia; 2010. $8081 \mathrm{p}$.

[11]. Ismail KM., editor. Perineal Trauma at Chilbirth. Switzerland: Springer; 2016. 89 p. 
[12]. Choirunissa R, Suprihatin S, Han H. Pengaruh Pijat Perineum Terhadap Kejadian Ruptur Perineum Pada Ibu Bersalin Primipara Di Bpm Ny "I" Cipageran Cimahi Utara Kota Cimahi Jawa Barat. J IIm Kesehat. 2019;11(2):124-33.

[13]. Anggraini Y, Martini D. Pada Ibu Bersalin Primipara Di Bpm Kecamatan Metro. J Kesehat [Internet]. 2015;VI(2):155-9. Available from: https://ejurnal.poltekkestjk.ac.id/index.php/JK/article/view/99

[14]. Juwita S dan PR. Asuhan Neonatus. 1st ed. Pasuruan Jawa Timur: Qiara Medika; 2020. 2-3 p.

[15]. Wijayanti HN. HUBUNGAN BERAT BADAN BAYI BARU LAHIR DENGAN KEJADIAN RUPTUR PERINEUM PERSALINAN NORMAL PADA IBU PRIMIGRAVIDA. PLACENTUM J IIm Kesehat dan Apl [Internet]. 2019 Feb 20;7(1):26. Available from: https://jurnal.uns.ac.id/placentum/arti cle/view/24992

[16]. Hastono S. Analisis Data Pada Bidang Kesehatan. 3rd ed. Jakarta: Rajawali Pers; 2018.
[17]. Rochmayanti, Sinta Nur dan Ummah K. Pijat Perineum Selama Kehamilan terhadap Kejadian Ruptur. M MN, editor. Surabaya: Jakad Media Publishing; 2019. 2-6 p.

[18]. Wirajaya, Agus dan Widya C. The Conny Method. 1st ed. Jakarta: Gramedia Pustaka Utama; 2015. 222 p.

[19]. Irawati D. Faktor yang Berhubungan dengan Ruptur Perineum di Puskesmas Puri Kabupaten Mojokerto. In: Faktor yang Berhubungan dengan Ruptur Perineum di Puskesmas Puri Kabupaten Mojokerto. Sekolah Tinggi Ilmu Kesehatan Majapahit; 2017. p. 227-73.

[20]. Pangastuti N. Robekan Perineum pada Persalinan Vaginal di Bidan Praktek Swasta (BPS) Daerah Istimewa Yogyakarta Indonesia Tahun. 2014;179-87..

[21]. Prawitasari E, Yugistyowati A, Kartika Sari D. Penyebab Terjadinya Ruptur Perineum pada Persalinan Normal di RSUD Muntilan Kabupaten Magelang. J Ners dan Kebidanan Indones. 2016;3(2):77 